\title{
The Homicide Witness and Victimization; PTSD in Civilian Populations: A Literature Review
}

Gerald M. Streets, M.D.

Thomas Jefferson University, Philadelphia, PA

Follow this and additional works at: https://jdc.jefferson.edu/jeffjpsychiatry

Part of the Psychiatry Commons

Let us know how access to this document benefits you

\section{Recommended Citation}

Streets, M.D., Gerald M. (1990) "The Homicide Witness and Victimization; PTSD in Civilian Populations: A Literature Review," Jefferson Journal of Psychiatry. Vol. 8 : Iss. 1 , Article 12.

DOI: https://doi.org/10.29046/JJP.008.1.007

Available at: https://jdc.jefferson.edu/jeffjpsychiatry/vol8/iss1/12

This Article is brought to you for free and open access by the Jefferson Digital Commons. The Jefferson Digital Commons is a service of Thomas Jefferson University's Center for Teaching and Learning (CTL). The Commons is a showcase for Jefferson books and journals, peer-reviewed scholarly publications, unique historical collections from the University archives, and teaching tools. The Jefferson Digital Commons allows researchers and interested readers anywhere in the world to learn about and keep up to date with Jefferson scholarship. This article has been accepted for inclusion in Jefferson Journal of Psychiatry by an authorized administrator of the Jefferson Digital Commons. For more information, please contact: JeffersonDigitalCommons@jefferson.edu. 


\title{
The Homicide Witness and Victimization; PTSD in Civilian Populations: A Literature Review
}

\author{
Gerald M. Streets, M.D.
}

People who witness the murder of an individual, whether a family member or acquaintance, often experience their loss as a psychic trauma. This described trauma is revealed by the symptom complex defined in the DSM-III-R as post-traumatic stress disorder (PTSD). Children, in particular, frequently suffer from debilitating grief, which hinders their emotional and cognitive development. This grief may masquerade as a learning disability, hyperactivity, or an attention deficit disorder. Witnessing murder and being victimized (i.e. rape, incest, and physical abuse) are equivalent experiences in their potential for generating massive intrapsychic conflict. Being poor is a predisposing factor which puts some groups at risk more than others. Further, the lack of therapeutic interventions enhances the likelihood of symptomatology and the perpetuation of intergenerational transmission. Few case reports have been written on the homicide witnesses' vulnerability to PTSD and their positive response to psychotherapy. There is an urgent need for more work in this area. The following review and case history present some of the current thoughts on these issues.

The incidence of murder, and victimization; defined in this paper as rape, incest, physical and verbal abuse, is increasing in many major cities in this country. The social and individual impact of witnessing murder and experiencing victimization is assumed to play an integral part in the neuropsychological and developmental psychopathology of; victimizers, people with antisocial personality traits, and borderline personality disorder (1). Witnessing murder and being victimized by a family member, significant other, or a stranger, are events which often produce "Psychic Trauma." "Psychic trauma is the emotional condition resulting from a sudden, unexpected, and intense external blow that overwhelms crucial coping and defensive operations, temporarily rendering the individual helpless"' (2). Psychic trauma was first defined by Freud (3) in 1920 as "a breach in the protective shield against stimuli" and in 1926 he stated that it is characterized by a sense of "utter helplessness" (4). Green wrote, "it is hard to imagine anything more terrifying to an infant or young child than to be

The author wishes to extend special thanks to Dr. Carl Bell, and the faculty of the Department of Psychiatry of Thomas Jefferson University Hospital, Jefferson Medical College. 
punched, kicked, burned, or hurled across the room without warning, by an uncontrolled parental figure from whom nurturance and protection are usually expected" (5). Steele observed that such children feel fundamentally unprotected. The parent no longer serves as an "Auxillary Stimulus Barrier" (6). The child must find ways to preserve the integrity of the self in the face of profound vulnerability and narcissistic injury. These ways often result in poor identity formation.

Children who are exposed to repetitive social and familial violence are more likely to be behaviorally and/or emotionally disturbed. The abused child, feeling helpless, frustrated and impotently enraged, then sees himself as bad and, perhaps therefore to blame for the abuse. At the same time, the child may identify with his aggressor and substitute for its "fears of helplessness and anihilation ... replacing them with feelings of power and omnipotence." (7) This may be seen in part as an identification with the abuser and in part as a drive for reenactment.

There has not been adequate research focused on the murder witness to validate either that; this traumatic event is a cause of post-traumatic stress disorder, or an anticedent of personality disorders. There have been studies on victimization however, which correlate with the theory. This presents a strong argument for the need of further studies and treatment interventions in this area. Studies that have been conducted on school age children and young adults support the idea that they will act out the psychological aftermath of their environment. A review of the literature by Kaufman and Zigler (8) gives an intergenerational transmission rate for abuse (from light bruises to those resulting in hospitalization) of $30 \% \pm 5$ for the best estimation. This figure is significantly less than any of the individual studies which they reviewed. Also it does not take into account the effect of constant exposure to victimization or the witnessing of murder outside of the home. Many of the children who merely witness violence suffer from post-traumatic stress disorder and have many other psychologic and behavioral disturbances in childhood and adult life (9).

Only a handful of studies have been done on the prevalence of positive victimization histories among inpatient and outpatient populations (10). Carmen et. al. (11), reviewed the psychiatric records of 188 adolescent and adult inpatients and found that $43 \%$ had histories of physical or sexual abuse or both, $22 \%$ had been physically abused, $8 \%$ had been sexually abused, and $12 \%$ had been both sexually and physically abused. Post et. al. (12), reported that $48 \%$ of the inpatients they interviewed had histories of battering relationships; $50 \%$ of the women reported having been battered and $21 \%$ of them had battered their partners, $14 \%$ of the men had been battered and $27 \%$ of them battered their partners. A survey conducted by Jenkins and Thompson in 1986 of 536 elementary school children from a Chicago community mental health center catchment area reported that $26 \%$ had seen someone shot and $29 \%$ had seen a stabbing (13). 
Presently there are only a handful of programs nationwide dealing with the tertiary treatment and research into this growing problem. Often it requires; a sniper attack on a school yard full of children, a psychopath's hijacking and kidnapping a bus load of school children or being labeled the number one murder capital in the country, (as in the case of Washington D.C.) before the need for primary intervention, evaluation and therapy becomes obvious.

"When one considers; the years of potential life lost from homicide, the cost of days lost from work, school and other meaningful activities, the cost of the disabilities resulting from violence, and the devastating emotional impact of violence-the true damage to society can be appreciated" (9). This was the emphasis of the statement of the American Psychiatric Association before the Select Committee on Children Youth and Families to the U.S. House of Representatives on Children and Violence presented by Carl C. Bell, May 6, 1989. Stark and Filteraft (14) delineated the fact that battered women suffer more frequently from general medical problems and psychological symptoms of stress such as suicide attempts, alcoholism, drug abuse, and depression. The full effect of witnessing such violence on children is unknown. Empirical observations of children in Philadelphia who have witnessed murder have revealed multiple cases of acute and chronic post-traumatic stress disorder. Philadelphia exceeded 500 murders for the year 1989.

There is strong evidence that acute PTSD symptoms occur in school age children with notable correlation between proximity to the violence and type and number of PTSD symptoms $(15,16)$. Many studies have shown the individual post-traumatic responses to be consistent with DSM-III-R criteria (17). In response to the recognizable stressors, children were reported to have symptoms of; reexperiencing $(18,19)$, numbing of responsiveness, and reduced involvement with the outside world. Incident specific, new symptoms and behaviors including autonomic hyperactivity were also seen. It is hypothesized that cortical neuronal and synaptic changes occur in PTSD as the consequence of excessive and prolonged sensitizing stimulation leading to depression of habituated learning. These changes are thought to involve structures concerned with aggressive expression and the sleep dream cycle (20). Shakoor, et. al. (21) surveyed over 1,000 students $(65 \%$ in high school and $35 \%$ in elementary school), and $39 \%$ reported having seen a shooting, $34 \%$ a stabbing, $23 \%$ a murder. An article by Dyson 1989 (22) illustrates that the severity of violence which inner city school children are faced with, drastically interferes with the child's ability to learn. "Intrusive imagery from violence within the family and its associated affects" which is often the result of an unassisted working through of the mourning process exhibited as aggression or violence, "markedly interferes with the child's ability to learn" (19).

Many of the studies of PTSD in witnesses of homicide and victims of abuse have been inconsistent in the selection of individual symptoms reported $(23,26,25,24,16)$. They lacked prior empirical studies to lend validity to the diagnosis in childhood $(27,26)$. There is presently an urgent need for more 
studies which are specific to the prevalence of the symptomatology of PTSD in witnesses of murder and violence. The following case history illustrates PTSD in an adolescent witness of murder.

\section{CASE HISTORY}

N.M. is a tall, quiet somewhat immature 14 year old female who presented for her first session with complaints of problems in school, manifested by poor concentration, day dreaming, difficulty remembering things, increasing anxiety, and an overall lack of interest in school. The initial history revealed that N.M. had recently taken a group of her younger siblings and cousins, ranging in ages from 4 to 11 years, to a local grocery store. While they were in the store purchasing their candy a gun battle ensued between two rival drug dealers. Apparently, the store also functioned as a retail distribution center for cocaine.

Two men stood inside of the store firing weapons at each other and at occupants of the store. Amid the screams and gunshots several of the children in the store found safety lying on the floor. From her vantage point of safety N.M. witnessed her 5 year old cousin being shot in the head. As he lay on the floor next to his older brother, N.M. could see that he was bleeding from his head and that his older brother's efforts to stop the bleeding by sticking his finger in the wound were ineffective.

\section{EVALUATION}

The initial interview was based on a format outlined by Pynoos, et. al. in 1986 (28). A structured Clinical Interview for DSM-III (SCID) for Post-Traumatic Stress Disorder was done (29). Approximately 3 weeks after the event N.M. appeared to be reexperiencing the trauma as evidenced by: recurrent and intrusive recollections of the event, recurrent dreams of the event, suddenly feeling as if the event were reoccurring because of an association with an environmental or ideational stimuli. This would occur whenever N.M. saw a newscast about drugs or had to walk past the store. Of great significance was the recurrent image of her dead cousin's body lying on her porch. This she encountered daily when coming home from school.

Numbing of responsiveness was exhibited by markedly diminished interest in school for this academically gifted child. N.M.'s feelings of estrangement resulted in her spending much time in her room where she would go inside her head "and kind of stare blankly into the room, not really seeing anything, almost like it didn't really happen." During this initial period, she also reported crying spells, early and late insomnia as well as being startled at events which she later described as being "silly" in retrospect. N.M.'s affect was restricted and for several months she was positive that it was all a mistake and that she was the one who was supposed to be dead. Clearly, N.M. had a diagnosis of acute PTSD. The patient denied the existance of any of these symptoms prior to the murder and this was validated by an objective report from her mother; and her previous scholastic achievements.

A review of her symptoms six months later showed a marked improvement; however she still met the criteria for chronic PTSD. N.M. continued to exhibit a preference of playing with her younger sibs and friends several years younger than herself. However she disliked the post-traumatic play that the younger children engaged in from time to 
time, because it increased her level of anxiety. This consisted of a game, a reenactment of the murder in which the children would shoot each other while eating candy, the ones being shot at would take refuge behind N.M.

It was during this time that the patient began to express her confusion about feeling withdrawn in social situations. "Some of my classmates are telling me that I'm getting too quiet," sometimes I don't know what to say at school or at home especially when I am with my older friends." N.M. was experiencing some difficulty in the development of identity formation as a result of the disruption of her psychosocial development. By staying close to her siblings she could protect them as she had been unable to do in the store. By engaging in their post-traumatic play she could undo the murder as the children came alive again after the game was over. Unfortunately this play only seemed to exacerbate her psychic trauma. Theoretically the way in which post-traumatic stress disorder symptoms will manifest depends in part on the developmental stages the individual is in at the time of the traumatic event (30). Traumatized adolescents have been described as having impaired identity formation as a result of disruption of their psychosocial development during the critical years when individual identity generally is established (31).

During the course of the initial history, special attention was paid to the patient's post-traumatic life experiences. The patient reported that she had been forced to have oral sex by an older boy in the neighborhood who had come into her house through an open door in the basement. This event occurred two years prior to the murder. The patient was seen for an initial medical evaluation, treated for gonorrhea and referred to a local sexual abuse clinic for follow-up. The patient did not attend due to the long waiting list.

In retrospect, the patient reported that she had had intrusive thoughts and nightmares about the event for about a month afterwards. She worked through the event with the support of her older sisters, "I just dealt with it", was the patient's response. In spite of this event, N.M. was noted to excel in her school work. A month after the event there were no noticable changes in her behavior according to her mother and teacher.

\section{TREATMENT}

N.M. was seen twice weekly in individual psychodynamic psychotherapy over a period of nine months. She also attended group therapy with her siblings and cousins, and family therapy. The individual therapy provided an environment in which N.M. was able to abreact, or experience an emotional release (catharsis) from remembering previously forgotten material; as well as reorder her thoughts, feelings, and perceptions regarding the overwhelming event. After a period of time she was able to assimilate the more frightening actualities, which had been obscured by constant fantasies, wishes, and the anxiety aroused by the post-traumatic play. She was able to openly discuss feelings of guilt and anxiety which were directly related to the murder, as well as the epiphenomena of the event. This included multiple recounts of the event through interviews with the news media and its portrayal of the event, as well as interviews by the police homicide unit and the District Attorney's office. N.M. was noted to have an escalation in her symptomatology around the time of the police line-up. She was extremely reluctant to participate in this because she feared that no matter what the outcome of the trial, the murderer would soon be back on the street. Through education and clarification along with appropriate interpretations in a combined approach of family and individual therapy, N.M. was able to make significant gains. 


\section{FAMILY THERAPY}

N.M. was seen in family therapy once weekly for approximately nine months. The entire family had experienced the upsetting incident together, and this modality allowed for a collective ventilation. It helped the psychologically stronger members of the family to better understand their own anger and denial, which was often hidden in their empathic response to the more rigid denial and intense or isolated affects of other members of the family.

During the first four months following the murder, the family was caught up in the celebrity like status imposed on them by the news media. This diminished their ability to mourn. During the fifth month, after the media attention had died down, N.M.'s mother was better able to understand her children's need to continue talking about the event. During one session the youngest member of the family who had also been shot, and the closest in age to the victim, began to talk about why he was writing his dead brother's name on the top of his school work. He stated that he wanted to keep his brother alive and that on several occasions his brother had been visible to him. He stated, "I see him standing in the playground, out there, looking at me." He expressed his confusion that no one in the family wanted to talk to him about his brother anymore, and that his closest living sibling was refusing to play with him because he kept asking questions about their brother who had been murdered. At this point in the session, the elder sibling was able to mention his fear of talking about his dead brother because he didn't want to "feel the pain again", and that it would disturb his fantasy of his brother being alive and well; vacationing with relatives in Virginia. Through the observation of this exchange N.M. and the other family members were able to discuss their fears about the reemergence of the intense anxiety that they had experienced in the first few months following their tragic loss. They were able to verbalize this fear only after multiple confrontations of their denial. Collectively they were better able to support their grieving process and empathically confront the fantasies of the other members of the family. L. Terr (2) has discussed the theory of contagion as it pertains to doing family therapy within cases where only one member is traumatized, while other siblings and adults are unaffected. She observes that the post-traumatic fears, play or distorted cognitive perceptual memories of one member may exacerbate the symptomatology of other members (32). This fear of contagion often results in the survivors finding themselves shut off from their acquaintances (33) and it represents part of the stigma associated with this population. It is my observation that contagion can occur in cases where members of an entire group have experienced either a common or unrelated traumatic event. Contagion can exacerbate individual symptomatology or further enhance isolation of affect and other dysfunctional defenses. Conjuntive individual therapy helps to diffuse contagion and aids the family by making them aware that they have more resources than each other to rely on. It also supplies family members with a method for understanding how to help each other at those times outside of the office when interventions are needed most.

\section{DISCUSSION}

The unnatural form of death, murder, dispels the comforting belief that there is protection from violence and inhumanity. This is reinforced by the investigative and judicial institutions of our society that force the bereaved to seek explanation and, or retribution $(34,35)$. Throughout life, carefully titrated amounts of frustration and stress are important to a persons psychological 
growth, often serving a vital function in stimulating movement from one developmental stage to another. Sometimes, the most valuable experiences are the painful ones, since they may add depth to the personality and increase the ability to empathize with others (36).

However, it is when one or many events become too painful, numerous or frequent, that the individual is unable to accommodate intrapsychically the assimilated events. One could postulate a kindling theory for PTSD, as we know intrapsychic representations share no temporal continuity and have an affinity which is as yet poorly understood.

It was through a supportive environment and encouragement to feel her pain while examining her cognitions that N.M.'s symptoms abated. She regained her confidence in herself and broadened her conceptualization of her sense of control which is an important contributor to a mental and physical image of well being. This in turn helped her to understand her feelings of loss of control as she was able to recognize the numerous triggers for her recurrent anxiety. After nine months she showed a marked improvement with almost total remission of many of the recorded symptoms.

It is the manner of dying rather than the event of death that determines the meaning of it, which in turn influences the form and course of subsequent bereavement (37-44). Although a preexisting schema of meaning, influenced by developmental conflicts and problems is incorporated into bereavement, specific kinds of dying create clinically distinct forms of grief (15).

\section{CONCLUSIONS}

1. Witnessing a murder can result in PTSD, which if not treated, can have grave consequences.

2. This case illustrates that appropriate treatment can ameliorate the damaging symptoms of psychic trauma caused by the traumatic event.

3. Because the prevalence of such violence is more concentrated in some groups, greater resources may need to be directed towards groups at risk.

4. Because the extent of this violence and the witnessing of it is so great, public health efforts should be mobilized to combat the problem.

\section{REFERENCES}

1. Herman JL, Vanderkolk BA: Traumatic anticedants of borderline personality disorder. In, Psychological Trauma. American Psychiatric Press, Inc., 111-126, 1987

2. Lenore C, Terr MD: Psychic trauma in children and adolescents. Psych Cls NA, 8(4, Dec):815-835, 1985

3. Freud S (1920): Beyond The Pleasure Principle. In Strachey J (ed): Standard Edition, Vol. 18, London, Hogarth Press, 1-64, 1955

4. Freud S (1920): Inhibitions, Symptoms, and Anxiety. In Strachey J (ed): Standard Edition, Vol. 20, London, Hogarth Press, 75-175, 1959 
5. Green A: Child abuse: A dimension of psychological trauma in abused children. J AM Acad Child Psych 22:231-237, 1983

6. Steele BF: Parental abuse of infants and small children. In Parenthood: Its Psychology And Psychopathology. Edited by Anthony EJ, Benidict T. Boston: Little Brown and Co., 1970

7. Galinas D: Persistent Vegetative Effects Of Incest. Psychiatry 47:312-332, 1983

8. Kaufman J, Zigler E: Do abused children become abusive parents. Am J Orthopsych 57:2, 186-192, 1987

9. Bell CC: Children and Violence: Statement of the American Psychiatric Association. Presented to Select Committee On Children, Youth and Families, U.S. House of Representatives, May 16, 1989

10. Bell CC, Taylor-Crawford $\mathrm{K}$, et al: Need for victimization screening in a black psychiatric population. J Nat Med Assoc 80:1, 41-48, 1988

11. Carmen E, Ricker PP, Mills T: Victims of violence and psychiatric illness. Am J Psych $141: 378-383,1984$

12. Post RO, Willet AB, Frank RD, et al: A preliminary report on the prevalence of domestic violence among psychiatric inpatients. Am J Psych 137:974-975, 1980

13. Jenkins EJ, Thompson B: Children Talk About Violence: Preliminary Findings From a Survey of Black Elementary School Children. Paper presented at the 19th Annual Convention of Association of Black Psychologists, Oakland, California, 1986

14. Stark E, Fliteraft A: Medical therapy as repression: The case of the battered woman. Health and Medicine Summer-Fall:29-32, 1982

15. Pynoos RS, Frederick C, Nader K, et al: Life threat and post-traumatic stress in school age children. Arch Gen Psych 44:1057-1062, 1984

16. Rynearson EK: Breavement after homicide: A descriptive study. Am J Psych 141(1 1): $1452-1454,1984$

17. American Psychiatric Association: Diagnostic and Statistical Manual of Mental Disorders, 3rd Ed., Revised. Washington, DC, American Psychiatric Association, 1987

18. Terr L: Children of chowchilla: Study of psychic trauma. Psychoanal Study Child 34:547-623, 1979

19. Pynoos R, Eth S: Children traumatized by witnessing acts of personal violence: Homicide, rape and suicide behavior. In Eth S, Pynoos R (eds): Post-Traumatic Stress Disorder In Children. Washington, D.C., American Psychiatric Press, 17-48, 1985

20. Kolb LC: A neuropsychological hypothesis explaining post-traumatic stress disorder. Am J Psych 144:8, 989-995, 1987

21. Shakoor B, Uhara CD: The Need for Co-victimization Screening In An Inner-City School Population. In Press.

22. Dyson JL: Family violence and its effect on childrens' academic under-achievement and behavioral problems in schools. J Natl Med Assoc. In Press.

23. Malmouist CP: Children who witness parental murder: Post-traumatic aspects. J Am Acad Child Psych 25:3, 320-325, 1986

24. Heimhlich EP: The use of paraverbal therapy in treating an inaccessible traumatized child. Am J Psychother 16:2, 4, 1987

25. Block D, Silber E, Perry S: Some factors in the emotional reactions of children to disaster. Am J Psych 113:416-422, 1956 
26. Zeanah C, Burk G: A young child who witnessed her mother's murder: Therapeutic and legal considerations. Am J Psychother 38:132-145, 1984

27. Senoir N, Gladstone T, Nurcombe: Child snatching: A case report. J Am Child Psych and Burk, ZC, Am J Psychother 38:132-145, 1984

28. Pynoos RS, Spencer ETH: Witness to violence: The child interview. J Am Acad Child Psych 25:3, 306-319, 1986

29. Spitzer RL, Williams JBW: Structured Clinical Interview For DSM III (SCID): Post-Traumatic Stress Disorder. Biometric Research Dept., New York State Psychiatric Institute 1983

30. Wilson JP, Smith WK, Johnson SK: A comparative analysis of pTSD among various survivor groups. In Figley CR (ed): Trauma And Its Wake. New York, Brunner/ Mazel 142-172, 1985

31. Lyons JA: Post-traumatic stress disorder. In Children And Adolescents: A Review of The Literature. Devel \& Behav Peds 8:6, 349-356, 1987

32. Miller K, Moore N, Lexius C: A group for families of homicide victims: An evaluation. J Cont Soc Work, September: 432-436, 1985

33. Deeich MR, Klass D: Special issues in the grief of parents of murdered children. Death Studies 11:81-87, 1987

34. Rynearson EK: Effects of unnatural dying on bereavement. Psych Annals 16:5, 273-275, 1986

35. Deeich MR, Klas D: Special issues in the grief of parents of murdered children. Death Studies 11:81-88, 1987

36. McDaniel E, McClelland P: Post-traumatic stress disorder. Practical Therapeutics, August 34(2):180-189, 1986

37. Sheskin A, Wallace S: Differing bereavements: Suicide, natural and accidental death. Omega 7:229-242, 1976

38. Volman R: The reactions of family systems to sudden and unexpecteds. Omega 2:101-106, 1971

39. Michalowski R Jr: The social meaning of violent death. Omega 7:83-93, 1976

40. Ziffon R, Olson E: The human meaning of total disaster: The buffalo experience. Psychiatry 39:1-18, 1976

41. Lehrman S: Reactions to untimely death. Psych Qrtly 30:546-578, 1956

42. Parks C: Bereavement: Studies Of Grief in Adult Life. New York, International Universities Press, 1973

43. Burgess A: Family reaction to homicide. Am J Onthopsych 45:391-398, 1975

44. Rynearson EK: Suicide internalized: An existential sequestrum. Am J Psych 138:8487, 1981

45. Bell CC, Griffith EE: Recent Trends in Suicide and Homicide Among Blacks. JAMA, 262:2265-2269, 1989

\section{OTHER SUGGESTED READINGS}

1. Eurst S: Psychic Trauma. New York, Basic Books, 1967

2. Ochberg FM: Post-Traumatic Therapy And Victims of Violence. Brunner/Mazel, Inc., 1988

3. Post-Traumatic Stress Disorder In Children. Spencer Eth and Robert S. Pynoos Editors, American Psychiatric Press, 1985 